\section{Intravitreal injection: balancing the risks}

NV Chong and T Adewoyin

\section{Eye (2007) 21, 313-316. doi:10.1038/sj.eye.6702699}

Intravitreal triamcinolone (iVTA) had gathered pace in the management of retinal diseases. By simply searching with the string 'intravitreal triamcinolone' in PubMed, it returns over 400 publications, with over 300 in the past 2 years. Despite the large number of publications, there are still very limited data on long-term efficacy (over 12 months). Furthermore, if one considers sham-controlled prospective randomised clinical trials (RCT) only, the efficacy is in doubt.

One of the original RCT in using iVTA in neovascular age-related macular degeneration (AMD) showed a negative result. ${ }^{1}$ Similar results were obtained in a more recent study on central retinal vein occlusion ${ }^{2}$ over 4 months. The difference between vision changes was significant only at 1 month. There was no meaningful difference in the occurrence of neovascularisation of the iris between the two groups. The only RCT with positive results is on diabetic macular oedema over 6 months from Jonas et al. ${ }^{3}$ The control group was only 12 eyes and laser treatment was not offered. When laser treatment was offered, there were no differences. ${ }^{4}$ Furthermore, when macular grid laser was performed 3 weeks after iVTA, visual outcome was better than iVTA alone especially at 6 months. $^{5}$

However, the complications of using iVTA are numerous; intraocular pressure rise and cataract are common occurrences. In a retrospective analysis in Southampton, the ocular morbidity is high $^{6}$ as well as the case report of ocular perforation ${ }^{7}$ and inadvertent administration of intralenticular injection. ${ }^{8}$ One would probably consider in the face of the lack of evidence that is unacceptably high.

Nevertheless, the introduction of this off-label treatment has not received any political problems in the UK. It is apparent to us that as triamcinolone is widely available in the NHS hospital formulary, is relatively inexpensive and hence can be used without going through any funding request nor special committees. It has become widely available. Nonetheless, failure to communicate to patients that iVTA treatment is off-label, might have medicolegal implication.

So are we seeing the same with the introduction of off-label used of Avastin? Several editorials in the UK, including in this journal $^{9}$ as well as the British Journal of Ophthalmology, ${ }^{10}$ have discussed the issues. As a recap, Avastin and Lucentis have presented with us an unprecedented dilemma. Lucentis is licensed in the US in June 2006 and is likely to be licensed in Europe, including the UK, in the first quarter of 2007. The clinical trial results of Lucentis were nothing short of amazing, with over $95 \%$ of patients attaining stabilisation and up to $40 \%$ with significant visual improvement. ${ }^{11,12}$ However, Lucentis is considered expensive. In the USA, Lucentis is priced at USD\$1950 per single use vial, given either monthly or of injections every 3 months after a three dose loading phase given every month. This reduced dosing regimen led to less impressive results than regular monthly dosing (PIER study, unpublished data).

Avastin is derived from the same murine antibody as Lucentis, has similar binding sites, but is a significantly larger molecule with potentially less effective retinal penetration. The affinity to those binding sites are of the order of 16-fold less. ${ }^{13}$ Nonetheless, in animal models, Avastin stays in the eye longer, although the half-life of Avastin when administered intravitreously in humans, is yet to be determined, and when given systemically in man for colorectal cancer, the half-life of Avastin has been reported at 21 days, significantly greater than $2 \mathrm{~h}$ with Lucentis. ${ }^{14,15}$ Hence, longer eye exposure of Avastin and increased systemic exposure compared to Lucentis might balance out the lower VEGF-binding affinity and the slower retinal penetration. ${ }^{16}$

On the basis of small-scale animal studies, ${ }^{17}$ Avastin may be safe leading to extensive but short-term, uncontrolled, widespread use in
Laser and Retinal Research Unit, King's College Hospital, Denmark Hill, London SE5 9RS, UK

Correspondence: NV Chong Tel: + 44203299 4598; Fax: +442032993738. E-mail: victor@ eretina.org 
humans worldwide. ${ }^{18}$ In a self-reported internet survey, the incidence of cataract and intraocular pressure rises were of the order of $0.01 \%$. In addition, of the possible systemic complications, only increases in blood pressure were recorded at an incidence of just over $0.2 \% .^{19}$

However, the report of intravitreal injection of Avastin in one eye for proliferative diabetic retinopathy, leading to a transient regression of new vessels in the other eye supports the concern of systemic absorption of Avastin. ${ }^{20}$ It is true the dosage might be small; however, being a monoclonal antibody, the effect of the dosage is often not linear. In other words, a small dose might have significant effects, which could be accumulative with repeated dosing.

It is also not unexpected that reports on complications of Avastin use are increasing. I was struck by one case report of two cases of endophthalmitis from the same batch of Avastin, as the Avastin vials used came from division of large commercially available preparation. The authors identified two different forms of bacteria in the two cases, and therefore, claimed that the division of the commercially available preparation is not to be blamed? I am not very sure that this conclusion is definitive. ${ }^{21}$

Doctors have also started using Avastin on patients who were excluded in all the AMD clinical trials; in particular, patients with pigment epithelial detachment. The hope was that it would not cause the RPE rip. Nonetheless, RPE rip has now been reported in patients treated with Macugen, ${ }^{22}$ Avastin, ${ }^{23,24}$ and Lucentis (PROTECT study, unpublished data). However, it is not certain whether the rip is because of natural history or because of the drug. But at least, this complication would have to be communicated with the patients.

I am not sure whether it is good or bad news, unlike other countries, Avastin mania has not spread over UK. It is restricted to be used in the private sector allowing only those who can afford it to benefit from this treatment while we are waiting for NICE to let us know whether we can use Lucentis in the NHS or not. There are also concerns whether we can afford the treatment or not.

Our primary concern as physicians and ophthalmologists is to provide the best for our individual patients, and not to prioritise services in the NHS. The BMJ editorial has mentioned that the NHS can save $£ 500$ millions per year, if all doctors prescribe a generic form of statin, which are licensed, proved to be safe, and equally effective. ${ }^{25}$ Combined with the reported multibillion pound overspend in the development of the new IT infrastructure for the NHS would fund Lucentis many times over.

Intravitreal injections will stay with us for sometime but fortunately it is not iVTA, otherwise we would have to perform many glaucoma surgery again. To use Avastin in the NHS, the following complex issues need to be addressed.

1. Is Avastin safe and effective in AMD?

As described above, small series of case studies, many of them retrospective analyses, have mentioned that Avastin is similar in efficacy in neovascular AMD to Lucentis at least in the short term. There is no evidence that it is better, so the usual criterion of unmet medical needs in using an off-label drug is not met after Lucentis is available in the NHS. The cost benefit is not enough to justify the use.

From a clinical evidence-based perspective, to justify using Avastin off-label over a licensed drug (Lucentis) for the same indication, we need at least a robust randomised, prospective controlled trial similar to a regulatory trial for drug-licensing purposes. A half-hearted trial will be a waste of resource, and would not give us the reassurance needed in terms of robustness of data. Hence, it is likely that number of centres involved in the study has to be small and the study has to be well funded with ring-fenced funding to ophthalmic departments involved in the study.

No matter how, the access of Lucentis for AMD patients should not be linked to such clinical trial.

2. Can we use Avastin after the trials?

There is still some doubt in my mind what would happen even if a robust clinical trial of Avastin vs Lucentis shows similar efficacy and safety. It is difficult for the UK government to endorse an off-label treatment over a licensed drug, given that the current druglicensing regulations governing antibodies (biological agents) are European Union and not UK-specific regulations (and thus difficult to amend and open to legal challenge from the European Union if not adhered to). It is equally difficult for the NHS to fund these drugs unless the process by which cost-effectiveness is assessed through the National Institute of Clinical Excellence (NICE) is also amended to include unlicensed therapies.

Looking again at the statins story, it has been estimated that the NHS could save approximately half a billion pounds by switching the prescriptions of branded licensed statins to generic licensed statins. ${ }^{25}$ The NHS has not done this when both drugs are licensed, so there has to be considerable doubt why they would endorse an off-label drug over a licensed one, even if it is similar in efficacy and safety, where there are potentially much greater medicolegal risks. When an ophthalmologist wants to use Avastin in AMD, he or she would need to provide fully informed consent; in other words, the patients have to be told that they are going to receive a cheaper alternative which is no better (Avastin) and offlabel (not considered by the regulatory authorities for the indication) whereas a licensed drug (Lucentis) is also available to them (assuming that NICE approves 
Lucentis as cost-effective). I wonder how many patients would choose Avastin if they were given the whole picture?

Could Primary Care Trusts (PCTs), who have to manage the financial considerations of the introduction of new medicines, restrict the use of Lucentis in favour of Avastin (as Avastin may offer reduced drug costs), once positive NICE guidance for Lucentis is available? I am not sure that anyone in the PCT would take the risk of potential legal challenge. So the risk taking would lie with the ophthalmologists again.

3. Should we use Avastin for other indications in the NHS?

Anecdotal experiences have suggested that Avastin is potentially useful in proliferative diabetic retinopathy, ${ }^{20}$ macular oedema secondary to retinal vein occlusion ${ }^{26}$ and pseudophakic cystoid macular oedema, ${ }^{27}$ and in early rubeosis. ${ }^{28}$ As there are no licensed products for these conditions, off-label use of Avastin might be justified. If we are going to spend research money, getting robust clinical trial data on these conditions might be more cost effective and beneficial to the community. Nonetheless, one could argue that once Lucentis and Macugen are available in the NHS, off-label use of Lucentis or Macugen under these conditions might be better as at least they are licensed intravitreal drugs. Cost implications might lead us to use Avastin instead.

As clinicians, we balance risks and look at benefits; that is what we do, but the repeated use of iVTA as a monotherapy clearly cannot be continued. In turn, we are at a stage where the use of Avastin is complex and full of hazards. The use of Lucentis, when licensed in the UK, would represent the safest option for us and patients, especially after NICE has endorsed Lucentis as costeffective. The cost of Lucentis might appear to be high, but it is still cheaper than blindness. Access to Lucentis should be available in the NHS as soon as possible.

\section{Acknowledgements}

Conflict of Interests: NVC has received honorarium, speaker fee, and travel grants from Novartis, Pfizer, and Iridex. TA has received travel grants from Novartis and Alcon. The authors' unit has received research support from Novartis, Pfizer, Allergan, and Iridex.

\section{References}

1 Gillies MC, Simpson JM, Luo W, Penfold P, Hunyor AB, Chua $\mathrm{W}$ et al. A randomized clinical trial of a single dose of intravitreal triamcinolone acetonide for neovascular agerelated macular degeneration: one-year results. Arch Ophthalmol 2003; 121(5): 667-673.
2 Ramezani A, Entezari M, Moradian S, Tabatabaei H, Kadkhodaei S. Intravitreal triamcinolone for acute central retinal vein occlusion; a randomized clinical trial. Graefes Arch Clin Exp Ophthalmol 2006, June 1 [E-pub ahead of print].

3 Jonas JB, Kamppeter BA, Harder B, Vossmerbaeumer U, Sauder G, Spandau UH. Intravitreal triamcinolone acetonide for diabetic macular edema: a prospective, randomized study. J Ocul Pharmacol Ther 2006; 22(3): 200-207.

4 Ockrim ZK, Senswathi S, Falk S, Ojeda F, Schadt M, Gregor $\mathrm{G}$ et al. A randomised trial of intravitreal triamcinolone versus macular laser therapy for persistent clinically significant diabetic macular oedema IOVS Supple ARVO abstract 2006. Program No. 5438.

5 Kang SW, Sa HS, Cho HY, Kim JI. Macular grid photocoagulation after intravitreal triamcinolone acetonide for diffuse diabetic macular edema. Arch Ophthalmol 2006; 124(5): 653-658.

6 Konstantopoulos A, Williams CP, Newsom RS, Luff AJ. Ocular morbidity associated with intravitreal triamcinolone acetonide. Eye 2006; 21(3): 317-320.

7 Ung I, Williams CPR, Canning CR. Globe rupture as a complication of intravitreal injection of triamcinolone. Eye 2007; 21(3): 423-424.

8 Rajak SN, Dubois VDPJ, Mokete B, Casswell AG. The inadvertent administration of intralenticular triamcinolone. Eye 2007; 21(3): 426-427.

9 Canning C, Lotery A. Bevacizumab: a new way of doing business? Eye 2006; 20(9): 985-987 [E-pub 2006, July 21].

10 Wong D, Kyle G. Some ethical considerations for the 'offlabel' use of drugs such as Avastin. Br J Ophthalmol 2006; 90(10): 1218-1219.

11 Brown DM, Kaiser PK, Michels M, Soubrane G, Heier JS, Kim RY et al. ANCHOR Study Group. Ranibizumab versus verteporfin for neovascular age-related macular degeneration. N Engl J Med 2006; 355(14): 1432-1444.

12 Rosenfeld PJ, Brown DM, Heier JS, Boyer DS, Kaiser PK, Chung CY et al. MARINA Study Group. Ranibizumab for neovascular age-related macular degeneration. $\mathrm{N}$ Engl J Med 2006; 355(14): 1419-1431.

13 Chen Y, Wiesmann C, Fuh G, Li B, Christinger HW, McKay $\mathrm{P}$ et al. Selection and analysis of an optimized anti-VEGF antibody: crystal structure of an affinity-matured Fab in complex with antigen. J Mol Biol 1999; 293(4): 865-881.

14 Gaudreault J, Fei D, Rusit J, Suboc P, Shiu V. Preclinical pharmacokinetics of Ranibizumab (rhuFabV2) after a single intravitreal administration. Invest Ophthalmol Vis Sci 2005; 46(2): 726-733.

15 Gordon MS, Margolin K, Talpaz M, Sledge Jr GW, Holmgren E, Benjamin R et al. Phase I safety and pharmacokinetic study of recombinant human anti-vascular endothelial growth factor in patients with advanced cancer. J Clin Oncol 2001; 19(3): 843-850.

16 Mordenti J, Cuthbertson RA, Ferrara N, Thomsen K, Berleau L, Licko V et al. Comparisons of the intraocular tissue distribution, pharmacokinetics, and safety of ${ }^{125} \mathrm{I}$ labeled full-length and Fab antibodies in rhesus monkeys following intravitreal administration. Toxicol Pathol 1999; 27(5): 536-544.

17 Manzano RP, Peyman GA, Khan P, Kivilcim M. Testing intravitreal toxicity of bevacizumab (Avastin). Retina 2006; 26(3): 257-261. 
18 Rosenfeld PJ. Intravitreal avastin: the low cost alternative to lucentis? Am J Ophthalmol 2006; 142(1): 141-143.

19 Fung AE, Rosenfeld PJ, Reichel E. The International Intravitreal Bevacizumab Safety Survey: using the internet to assess drug safety worldwide. Br J Ophthalmol 2006; 90(11): 1344-1349 [E-pub 2006 Jul 19].

20 Avery RL, Pearlman J, Pieramici DJ, Rabena MD, Castellarin AA, Nasir MA et al. Intravitreal bevacizumab (Avastin) in the treatment of proliferative diabetic retinopathy. Ophthalmology 2006; 113(10): 1695 e1-e15.

21 Aggio FB, Farah ME, de Melo GB, D'Azevedo PA Pignatari ACC, Höfling-Lima AL. Acute endophthalmitis following intravitreal bevacizumab (Avastin) Injection. Eye 2007; 21(3): 408-409.

22 Singh RP, Sears JE. Retinal pigment epithelial tears after pegaptanib injection for exudative age-related macular degeneration. Am J Ophthalmol 2006; 142(1): 160-162.

23 Meyer CH, Mennel S, Schmidt JC, Kroll P. Acute retinal pigment epithelial tear following intravitreal bevacizumab
(Avastin) injection for occult choroidal neovascularisation secondary to age related macular degeneration. $\mathrm{Br} \mathrm{J}$ Ophthalmol 2006; 90(9): 1207-1208.

24 Bakri SJ, Patel SP. Retinal pigment epithelial tear following intravitreal bevacizumab. 2007; 21(3): 424-425.

25 Moon JC, Bogle RG. Switching statins. BMJ 2006; 332(7554): 1344-1345.

26 Iturralde D, Spaide RF, Meyerle CB, Klancnik JM, Yannuzzi LA, Fisher YL et al. Intravitreal bevacizumab (Avastin) treatment of macular edema in central retinal vein occlusion: a short-term study. Retina 2006; 26(3): 279-284.

27 Mason JO, Albert Jr MA, Vail R. Intravitreal bevacizumab (Avastin) for refractory pseudophakic cystoid macular edema. Retina 2006; 26(3): 356-357.

28 Avery RL. Regression of retinal and iris neovascularization after intravitreal bevacizumab (Avastin) treatment. Retina 2006; 26(3): 352-354. 